\title{
Retrospective evaluation of pain in patients with coccydynia who underwent impar ganglion block
}

\author{
Ozlem Sagir ${ }^{*}$, Hafize Fisun Demir, Fatih Ugun and Bulent Atik
}

\begin{abstract}
Background: We aimed to evaluate pain scores one year after impar ganglion block in patients with coccydynia who did not benefit from conservative treatment.

Methods: The medical records of 29 patients with coccydynia were reviewed. Patients who were referred to the algology clinic and underwent impar ganglion blocks were retrospectively evaluated. Demographic data, time to the onset of pain, causes of pain, X-ray findings, administered invasive procedures, and visual analog scale (pain) scores were recorded.

Results: A total of 29 patients were included in the study, 10 males (34\%) and 19 females (66\%). The average age and body mass index were $53.45 \pm 9.6$ and $29.55 \pm 4.21$ respectively. In 21 patients, the onset of pain was associated with trauma. Nineteen patients (65.5\%) had anterior coccygeal angulation. The average visual analog scale score before undergoing an impar ganglion block was $7.4 \pm 1$. After the procedure, the scores at $<3$ months, $3-6$ months and 6 months- 1 year follow-up intervals were significantly lower $(p<0.05)$. Furthermore, visual analog scale scores at the 3-6 months and 6 months-1 year periods were significantly lower in patients who received diagnostic blocks plus pulse radiofrequency thermocoagulation than in patients who underwent a diagnostic block only.
\end{abstract}

Conclusions: The impar ganglion block provides effective analgesia without complications in patients with coccydynia. Pulse radiofrequency thermocoagulation combined with a diagnostic block prolongs the analgesic effect of the procedure.

Keywords: Coccyx, Chronic pain, Sympathetic nerve block, Pain management, Pulsed radiofrequency treatment

\section{Background}

Coccydynia is defined as pain in the sacrococcygeal region. It is a disorder that not only reduces a patient's quality of life, but it is difficult to treat [1]. Numerous physiological and psychological causes can contribute to its etiology. Typically, it is related to chronic inflammation triggered by abnormal mobilization of the coccygeal structures. Childbirth as well as minor but repetitive and direct trauma are considered as possible causal factors. Coccydynia is rarely

\footnotetext{
* Correspondence: ozlemsagir@yahoo.com

Department of Anesthesiology, Balıkesir University Health Application and Research Hospital, 10100 Balikesir, Turkey
}

related to neoplasms or psychological conditions such as somatization [2, 3]. Its incidence is unknown, but female gender and obesity increase the risk [4].

Patients with coccydynia typically complain of pain in the coccyx. This pain increases with prolonged sitting, leaning backwards during sitting, prolonged standing and standing up after being in a sitting position. Conservative treatments such as non-steroidal, anti-inflammatory drugs (NSAIDs), levator ani relaxation exercises, sitting cushions and transcutaneous electrical simulation have all been used to alleviate the pain, however these methods are ineffective in $10 \%$ of patients [2].

(c) The Author(s). 2020 Open Access This article is licensed under a Creative Commons Attribution 4.0 International License, which permits use, sharing, adaptation, distribution and reproduction in any medium or format, as long as you give appropriate credit to the original author(s) and the source, provide a link to the Creative Commons licence, and indicate if changes were made. The images or other third party material in this article are included in the article's Creative Commons licence, unless indicated otherwise in a credit line to the material. If material is not included in the article's Creative Commons licence and your intended use is not permitted by statutory regulation or exceeds the permitted use, you will need to obtain permission directly from the copyright holder. To view a copy of this licence, visit http://creativecommons.org/licenses/by/4.0/ The Creative Commons Public Domain Dedication waiver (http://creativecommons.org/publicdomain/zero/1.0/) applies to the data made available in this article, unless otherwise stated in a credit line to the data. 
The impar ganglion, also known as the Walther ganglion, is the terminal pelvic division of the sympathetic chain and is located behind the rectum, anterior to the sacrococcygeal joint and coccyx. It provides nociceptive and sympathetic innervation to the perineum [5]. When conservative treatments fail to alleviate pain in patients with coccydynia, the impar ganglion can be blocked through the sacrococcygeal or the intercoccygeal junction with the help of screening techniques. After insertion and confirmation of the needle position, local anesthetic drugs, either with or without steroids are injected and thermal ablation via radiofrequency may be applied. However there is limited clinical evidence to support the efficacy of these interventions [6].

The aim of our study was to evaluate pain scores in patients with coccydynia who underwent an impar ganglion block in our algology department due to the failure of conservative treatment over the course of a 1-year follow-up period.

\section{Methods}

The medical records of 29 coccydynia patients treated with impar ganglion block at the algology department of Balikesir University Hospital were retrospectively reviewed. Age, gender, height, body weight, the onset of pain and its possible causes (falls, accidents, cancer, or idiopathic) were collected from medical records. X-ray images of the coccyx were examined to evaluate coccygeal structure and underlying physiology and potential pathologies. The images were classified as either normal or exhibiting anterior coccygeal angulation. Our study was approved by the institutional ethics committee (decision No: 2018/156).

The number of impar ganglion blocks used on patients, the $0.25 \%$ bupivacaine $+40 \mathrm{mg}$ methylprednisolone mixture used, and the application of radiofrequency thermocoagulation (RFT) were recorded. Visual analog scale (VAS) pain scores were acquired from the records both before and after the procedures. The VAS scores were obtained during policlinic check-ups and phone calls at $<3$ months, 3-6 months and 6 months- 1 year time intervals following the procedure. Patients who were referred to surgery after the procedure were also recorded, along with their VAS scores.

The impar ganglion block was performed using a 22gauge needle from the midline. The tip of the needle and the spread of the radiopaque substance in front of the coccyx were observed using fluoroscopic lateral images with C-arm fluoroscopy assistance (Fig. 1). Blocks performed total $10 \mathrm{~mL}$ volume with $0.25 \%$ bupivacaine+ $40 \mathrm{mg}$ methylprednisolone were classified as a diagnostic impar block (DB). After the DBs were performed, patients who subsequently underwent pulse RFT (NeuroTherm NT 1100 , USA) at $42{ }^{\circ} \mathrm{C}$ for 2 min with a $22-\mathrm{G}$

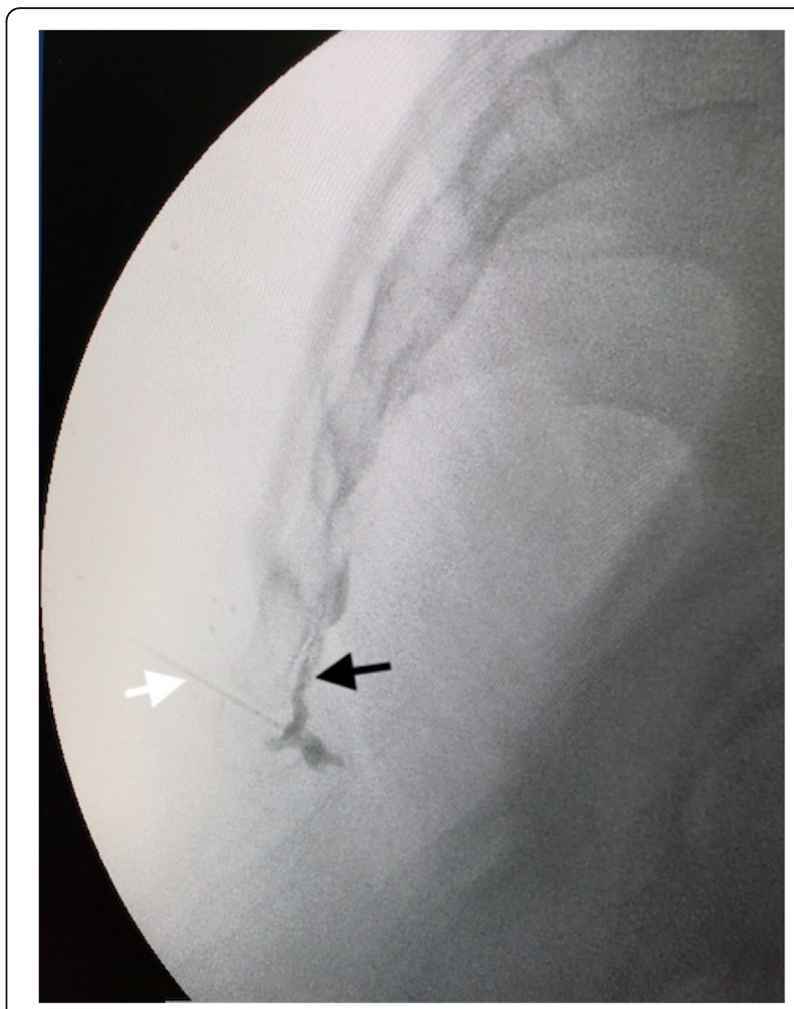

Fig. 1 Lateral fluoroscopy view of the impar ganglion block. Application of the needle from the sacrococcygeal junction (white arrow) and confirmation of the location of the needle tip and spreading of the radiopaque dye in the anterior part of the sacrococcygeal joint (black arrow)

insulated RFT needle with a $5 \mathrm{~mm}$ active tip were classified as DB + RFT.

Data was analyzed using IBM SPSS Statistics version 22 (IBM Corp., Armonk, NY, USA). Continuous data is expressed as averages and standard deviations and categorical data as frequencies and percentages. The Shapiro-Wilk test was used to evaluate the normal distribution of parameters. Comparisons of the data was performed using the Wilcoxon and Mann-Whitney $U$ test. Parametric data is shown as average \pm standard deviation (SD). Association among VAS score, gender, and body mass index was carried out using the Spearman's correlation test. A $p$-value $<0.05$ was accepted as statistically significant.

\section{Results}

Twenty-nine patients, 10 males (34\%) and 19 females (66\%) were included in the study. The average age, weight, height and body mass index (BMI) of all patients was $53.45 \pm 9.6$ years, $82.59 \pm 12.12 \mathrm{~kg}, 166.21 \pm 8.8 \mathrm{~cm}$ and $29.55 \pm 4.21$, respectively. Body mass index was over 25 in 23 of 29 patients (79.3\%). The onset of pain was greater than 1 year in $23(79.3 \%)$ patients and less than 1 year in 6 patients (20.7\%) (Table 1). Seventeen patients 
Table 1 Examination findings from 29 patients with coccydynia

\begin{tabular}{ll}
\hline Weight characteristics & $\mathrm{n}(\%)$ \\
\hline $\mathrm{BMI}<25$ & $6(20.7)$ \\
$\mathrm{BMI} 25-29.9$ & $8(27.6)$ \\
$\mathrm{BMI} \geq 30$ & $15(51.7)$ \\
Time of pain onset & \\
$\quad<1$ year & $6(20.7)$ \\
$>1$ year & $23(79.3)$ \\
Causes of pain & \\
Falling & $17(58.6)$ \\
Traffic accident & $4(13.8)$ \\
Neoplasm & $2(6.9)$ \\
Idiopathic & $6(20.7)$ \\
X-ray findings & \\
Normal & $10(34.5)$ \\
Anterior angulation & $19(65.5)$ \\
\hline
\end{tabular}

(58.6\%) reported pain after falling backwards, and 4 (13.8\%) experienced pain following a traffic accident. In 2 patients $(6.9 \%)$ the pain was due to cancer and in 6 patients $(20.7 \%)$ it was idiopathic (Table 1). X-ray evaluations were normal in 10 patients (34.5\%), while an anterior coccygeal angulation was found in 19 patients (65.5\%) (Table 1).

Twenty patients (68.9\%) underwent DB only, while 9 (31.1\%) underwent DB+ pulse RFT. In all patients, a DB with a total of $10 \mathrm{ml}$ of $0.25 \%$ bupivacaine+ $40 \mathrm{mg}$ methylprednisolone was administered during the first procedure. The block was performed using either a transsacrococcygeal or intercoccygeal approach.

The average VAS score before undergoing the impar ganglion block was $7.4 \pm 1$ and decreased to $5.2 \pm 1.5$ following the procedure. At the 3-month evaluation period, the average VAS score was $4.7 \pm 2.1$, and at the 3-6 month and 6 month-1 year evaluations the scores were $4.3 \pm 2.4$ and $4.2 \pm 2.6$, respectively. VAS scores were found to be significantly lower in patients at the 3month, 3-6 months and 6 months- 1 year follow-up evaluations $(p<0.05)$ (Table 2). VAS scores before the block, after the block and in the first 3-month follow-up period were similar in both the DB block and DB+ pulse RFT block groups. However, patients who received RFT had significantly lower VAS scores at the 3-6 months and 6 months-1 year follow-up periods (Table 3 ). In these periods, VAS score was lower than 4 in 9 patients who received DB block and in 8 patients who received DB + pulse RFT block. Percentage of improvement in pain score after treatment were $40 \%$ in DB block and $72 \%$ $\mathrm{DB}+\mathrm{RFT}$ block. The patients were allowed to take gabapentin, pregabalin or a single tablet of tramadol and paracetamol $(37.5 \mathrm{mg}+325 \mathrm{mg})$ combination when
Table 2 Average VAS scores of impar ganglion block patients

\begin{tabular}{lll}
\hline Observation time & VAS $($ Mean \pm SD $)$ & $P$-value \\
\hline Before the block & $7.4 \pm 1$ & \\
After the block & $5.2 \pm 1.5$ & $<0.001$ \\
$<3$ months & $4.7 \pm 2.1$ & $<0.001$ \\
$3-6$ months & $4.3 \pm 2.4$ & $<0.001$ \\
6 months-1 year & $4.2 \pm 2.6$ & $<0.001$ \\
\hline VAS Visual Analog Scale; Values compared with the average value before the \\
block $p<0.01$
\end{tabular}

required. In 4 patients, the VAS scores remained $\geq 7$ throughout all of the follow-up measurements (3 patients in the DB group and 1 patient in the $\mathrm{DB}+$ pulse RFT group). These patients were referred to surgery for coccyx excision.

There was no correlation between VAS scores and gender or BMI.

\section{Discussion}

A 1-year follow-up of coccydynia patients demonstrated that the impar ganglion block procedure effectively controlled pain and that a DB + pulse RFT further prolonged analgesic efficacy. Coccydynia is a symptom with different causal factors including twisting of the sacrococcygeal joint or intercoccygeal segment, fracture, infection, tumor or degenerative changes [2]. These factors can lead to localized pain at the coccygeal site, which increases while in a seated position. Pain is the diagnostic symptom, especially in the coccyx and sacrococcygeal areas, as demonstrated during physical examination and through radiologic screening. Conservative treatments include oral analgesic drugs, use of a sitting cushion, physiotherapy, massage, psychotherapy and manipulation [6]. An impar ganglion block is an option when conservative treatment is insufficient; therefore, in this study, we evaluated the efficacy of the impar ganglion block in patients who did not benefit from conservative treatment.

The impar ganglion is the terminal division of the sympathetic chain located in the midline and, in contrast to other divisions, is the only solitary autonomic

Table 3 Comparison of average VAS scores in diagnostic and radiofrequency impar ganglion block groups

\begin{tabular}{llll}
\hline Observation time & $\begin{array}{l}\mathrm{DB} \\
(n=20)\end{array}$ & $\begin{array}{l}\mathrm{DB}+\mathrm{RFT} \\
(n=9)\end{array}$ & $P$-value \\
\hline Before the block & $7.4 \pm 0,9$ & $7.5 \pm 1.1$ & 0.729 \\
After the block & $5.5 \pm 1.5$ & $4.5 \pm 1.4$ & 0.127 \\
$<3$ months & $5.2 \pm 2.3$ & $3.7 \pm 1.2$ & 0.085 \\
$3-6$ months & $5 \pm 2.5$ & $3 \pm 1.8$ & 0.044 \\
6 months-1 year & $5 \pm 2.4$ & $2.4 \pm 2.1$ & 0.010 \\
\hline
\end{tabular}

DB Diagnostic block, RFT Radiofrequency thermocoagulation 
division. The definitive anatomic location of the impar ganglion remains uncertain but is considered to be anterior to the sacrococcygeal joint, coccyx or distal end of the coccyx [7]. Different approaches to accessing the ganglion using screening techniques such as fluoroscopy, ultrasonography and computerized tomography to view the tip of the needle during the procedure have been described in the literature [8-10]. The sacrococcygeal joint is closed in $51 \%$ of patients, which makes access from the intercoccygeal area easier for the physician [11]. The blocks in this study were performed using transsacrococcygeal and intersacrococcygeal approaches with the assistance of fluoroscopy.

Coccydynia occurs more frequently in females. While it can occur at any age, the incidence increases in people over forty [12]. Consistent with the literature, $66 \%$ of our patients were female and the average age was $53.45 \pm 9.6$. A high BMI is also a known risk factor for coccydynia, and, in our study, the average patient had a BMI of $29.55 \pm 4.21$, which is close to the obesity cut-off value [13]. We observed a tendency of patients to be overweight and obese, but there was no association between the BMI and patient's VAS scores.

Gündüz et al. noted that trauma, especially after a backwards fall, was the cause of coccydynia in $50 \%$ of patients [14]. Similar to this finding, trauma was the leading cause of coccydynia in our study: $58.6 \%$ experienced a fall and for $13.8 \%$, a traffic accident was the origin. X-rays and magnetic resonance imaging are useful tools for diagnosing sarcococcygeal hypermobility, hypomobility, fracture and luxation, especially in cases of trauma [15]. In our patients, only X-ray images could be evaluated and were found to be normal in 10 patients (34.5\%), while coccygeal angulation at the distal end was observed in the remaining 19 patients (65.5\%).

Pain relief can be achieved with conservative medical treatment in $90 \%$ of patients with coccydynia [16, 17]. Patients referred to our policlinic were treated with multiple analgesics including NSAIDs, paracetamol and seating cushions. An impar ganglion block was performed if the VAS score remained $\geq 4$ despite conservative treatment. Under fluoroscopy, 20 patients (68.9\%) received only DB, and 9 patients (31.1\%) received DB + pulse RFT at $42{ }^{\circ} \mathrm{C}$ for $2 \mathrm{~min}$ at the impar ganglion area. Gonnade et al. reported a significant decrease in pain in 31 patients following impar ganglion blocks in a 1-year follow-up study [18]. We observed a similar significant reduction in pain scores in our patients. The average VAS score was $7.4 \pm 1.6$ before the block, which then significantly decreased in the first 3 months, 3-6 months and 6 months- 1 year evaluations post-procedure.

Radiofrequency treatment is a percutaneous and minimally invasive procedure that can be used in coccydynia patients who do not benefit from appropriate medical treatment and physiotherapy. It is more selective compared to phenol and alcohol neurolysis and leads to fewer complications. Reig et al. reported impar ganglion blocks with RFT as useful for non-malignant perineal pain [8]. Similarly, Kurcelli et al. observed a significant decrease in pain scores, without complications, after impar ganglion block with RFT in patients with chronic coccydynia, except in 2 patients for whom the decrease in pain scores after RFT was no more than 50\% [19]. In our study, 4 patients ( 3 in the DB and 1 in the DB+ pulse RFT group) did not benefit from treatment and were referred to coccyx-excision surgery.

Serious complications such as rectal perforation, hemorrhage and infection, along with difficulties in implementing the technique, restrict the popularity of this highly effective block [6]. In all of our patients, the blocks were performed after both the needle tip and the spread of the radiocontrast substance was confirmed at the relevant area under fluoroscopy. No complications occurred during or after the procedure.

Surgical excision of the coccyx for the treatment of coccydynia is the option of last resort and is performed only if all other treatments have failed. High complication rates and failure to relieve pain have been reported with this procedure, but its overall success rate is between 51 and $90 \%[15,20]$. In 4 of our patients who underwent surgical coccyx excision due to insufficient pain relief with conservative and interventional treatments, their VAS scores decreased to $\leq 2$ following surgery in 2 patients but remained between 5 and 6 in the other 2 .

Limitations to our study include its relatively small sample size and the retrospective nature of the review. The impar ganglion block provides effective pain relief without complications in patients with coccydynia. Diagnostic blocks combined with pulse RFT achieved prolonged analgesic efficacy. However, prospective randomized studies involving larger sample sizes are needed to reach more conclusive results regarding the effectiveness of these procedures.

\section{Conclusions}

İn conclusion, impar ganglion block is an effective procedure with low complication rate for pain relief in coccydynia. The analgesic effect can be prolonged by combining the DB with pulse RFT.

\section{Abbreviations}

NSAIDs: Non-steroidal, anti-inflammatory drugs; RFT: Radiofrequency thermocoagulation; VAS: Visual analog scale; DB: Diagnostic impar block; BMI: Body mass index

Acknowledgements

None. 


\section{Authors' contributions}

Concept and design- OS. Materials - Data Collection and/or Processing - OS, HFD, FU. Analysis and/or Interpretation - OS., FU, BA. Literature Search - OS, HFD, FU, BA. Writing Manuscript - OS, HFD, BA. Revised the draft paper - OS, HFD, FU, BA. The authors have read and approved the manuscript.

\section{Funding}

None.

\section{Availability of data and materials}

The datasets used and/or analysed during the current study are available from the corresponding author on reasonable request.

\section{Ethics approval and consent to participate}

This retrospective study was approved by the Balikesir University Medical Faculty Ethics Committee (number: 2018/156, Chairperson Prof. Fuat Erel) on 26th September 2018. The study was conducted using the data obtained from Picture Archiving and communication system (PACS) database and hospital information management system database.

\section{Consent for publication}

Not applicable.

\section{Competing interests}

None.

Received: 20 February 2020 Accepted: 6 May 2020

Published online: 11 May 2020

\section{References}

1. Patijn J, Janssen M, Hayek S, Mekhail N, Zundert JV, Kleef MV. Coccygodynia. Pain Pract. 2010;10:554-9.

2. Lirette LS, Chaiban G, Tolba R, Eissa H. Coccydynia: an overview of the anatomy, etiology, and treatment of coccyx pain. Ochsner J. 2014;14:84-7.

3. Nathan ST, Fisher BE, Roberts CS. Coccydynia: a review of pathoanatomy, aetiology, treatment and outcome. J Bone Joint Surg Br. 2010;92:1622-7.

4. Maigne JY, Doursounian L, Chatellier G. Causes and mechanisms of common coccydynia: role of body mass index and coccygeal trauma. Spine (Phila Pa 1976). 2000;25:3072-9.

5. Peng $\mathrm{P}$, Narouze $\mathrm{S}$. Ultrasound-guided interventional procedures in pain medicine: a review of anatomy, sonoanatomy and procedures. Part I: nonaxial structures. Reg Anesth Pain Med. 2009;34:458-74.

6. Elkhashab Y, Ng A. A review of current treatment options for Coccygodynia. Curr Pain Headache Rep. 2018;19:22-8.

7. Oh CS, Chung IH, Ji HJ, Yoon DM. Clinical implications of topographic anatomy on the ganglion impar. Anesthesiology. 2004;101:249-50.

8. Reig E, Abejón D, del Pozo C, Insausti J, Contreras R. Thermocoagulation of the ganglion impar or ganglion of Walther: description of a modified approach. Preliminary results in chronic, nononcological pain. Pain Pract. 2005:5:103-10.

9. Agarwal-Kozlowski K, Lorke DE, Habermann CR, Amm Esch JS, Beck H. CTguided blocks and neuroablation of the ganglion impar (Walther) in perineal pain: anatomy, technique, safety and efficacy. Clin J Pain. 2009;25: 570-6.

10. Lin CS, Cheng JK, Hsu YW, Chen CC, Lao HC, Huang CJ, et al. Ultrasoundguided ganglion impar block: a technical report. Pain Med. 2010;11:390-4.

11. Postacchini F, Massobrio M. Idiopathic coccygodynia. J Bone Joint Surg Am. 1983;65A:1116-24.

12. Fogel GR, Cunningham PY, Esses SI. Coccygodynia: evaluation and management. J Am Acad Orthop Surg. 2004;12:49-54.

13. Maigne JY, Pigeau I, Aguer N, Doursounian L, Chatellier G. Chronic coccydynia in adolescents. A series of 53 patients. Eur J Phys Rehabil Med. 2011:47:245-51.

14. Gunduz OH, Sencan S, Kenis-Coskun O. Pain relief due to Transsacrococcygeal ganglion Impar block in chronic Coccygodynia: a pilot study. Pain Med. 2015;16:1278-81.

15. Pennekamp PH, Kraft CN, Stütz A, Wallny T, Schmitt O, Diedrich O. Coccygectomy for coccygodynia: does pathogenesis matter? J Trauma. 2005;59:1414-9.

16. Capar B, Akpinar N, Kutluay E, Müjde S, Turan A. Coccygectomy in patients with coccydynia [in Turkish]. Acta Orthop Traumatol Turc. 2007;41:277-80.
17. Trollegaard AM, Aarby NS, Hellberg S. Coccygectomy: an effective treatment option for chronic coccydynia: retrospective results in 41 consecutive patients. J Bone Joint Surg Br. 2010;92:242-5.

18. Gonnade N, Mehta N, Khera PS, Kumar D, Rajagopal R, Sharma PK. Ganglion impar block in patients with chronic coccydynia. Indian J Radiol Imaging. 2017:27:324-8.

19. Kırcelli A, Demirçay E, Özel Ö, Çöven I, Işık S, Civelek E, et al. Radiofrequency Thermocoagulation of the ganglion Impar for Coccydynia management: long-term effects. Pain Pract. 2019;19:9-15.

20. Foye PM. Coccydynia: tailbone pain. Phys Med Rehabil Clin N Am. 2017;28: $539-49$

\section{Publisher's Note}

Springer Nature remains neutral with regard to jurisdictional claims in published maps and institutional affiliations.
Ready to submit your research? Choose BMC and benefit from:

- fast, convenient online submission

- thorough peer review by experienced researchers in your field

- rapid publication on acceptance

- support for research data, including large and complex data types

- gold Open Access which fosters wider collaboration and increased citations

- maximum visibility for your research: over $100 \mathrm{M}$ website views per year

At $\mathrm{BMC}$, research is always in progress.

Learn more biomedcentral.com/submissions 